Purdue University

Purdue e-Pubs

CTRC Research Publications

Cooling Technologies Research Center

2009

\title{
Microscale Temperature Measurements near the Triple Line of an Evaporating Thin Liquid Film
}

H. K. Dhavalewsarapu

S V. Garimella

Purdue University, sureshg@purdue.edu

J.Y.Murthy

Follow this and additional works at: http://docs.lib.purdue.edu/coolingpubs

Dhavalewsarapu, H. K.; Garimella, S V.; and Murthy, J. Y., "Microscale Temperature Measurements near the Triple Line of an Evaporating Thin Liquid Film" (2009). CTRC Research Publications. Paper 262.

http://dx.doi.org/10.1115/1.3090525

This document has been made available through Purdue e-Pubs, a service of the Purdue University Libraries. Please contact epubs@purdue.edu for additional information. 


\section{Microscale Temperature}

Measurements Near the Triple

Line of an Evaporating Thin

Suresh V. Garimella ${ }^{1}$

e-mail: sureshg@purdue.edu

\author{
Jayathi Y. Murthy \\ Cooling Technologies Research Center, \\ School of Mechanical Engineering, \\ and Birck Nanotechnology Center, \\ Purdue University, \\ 585 Purdue Mall, \\ West Lafayette, IN 47907-2088
}

Liquid Film

Thin-film evaporation from a meniscus in a confined space, which is the basis for many two-phase cooling devices, is experimentally investigated. The meniscus formed by heptane, a highly wetting liquid, on a heated fused quartz wafer is studied. Microscale infrared temperature measurements performed near the thin-film region of the evaporating meniscus reveal the temperature suppression caused by the intensive evaporation in this region. The high spatial resolution $(\sim 6.3 \mu \mathrm{m})$ and high temperature sensitivity $(\sim 20 \mathrm{mK})$ of the infrared camera allow for improved accuracy in the measurements. The effects of evaporation rate, applied heat flux, and channel width on the thin-film heat transfer distribution are also explored. [DOI: 10.1115/1.3090525]

Keywords: meniscus, thin liquid film, evaporation, diffusion, triple line

\section{Introduction}

Evaporation from a meniscus serves as the basic mechanism in many two-phase cooling devices such as heat pipes, thermosyphons, vapor chambers, two-phase cold plates, and capillary pumped loops. Thin-film evaporation, which takes place near a solid-liquid-vapor junction, has long been believed to be the dominant mode of heat transfer in such systems [1]. The efficacy of heat transfer in thin films is attributed to a high disjoining pressure gradient [2], which results in liquid being pulled into the thin-film region, as well as the very low thermal resistance resulting from the small film thickness. The intensive evaporation near the triple line creates a temperature gradient along the meniscus. This results in a surface tension gradient that gives rise to thermocapillary convection. Both the evaporation from the thin film as well as the thermocapillary convection induced have been reported in the literature $[3,4]$ to play a major role in the total heat transferred. However, the exact role and nature of these processes is still not completely understood.

Wayner [5] carried out extensive theoretical and experimental studies in this field and delineated several important factors influencing thin-film evaporation. Ma and Peterson [6] developed experimentally verified models for evaporation from V-grooves to predict their maximum heat transport limit. Holm and Goplen [7] were the first to develop an approximate method for predicting heat transfer from capillary grooves. They found that nearly $80 \%$ of the total heat transfer takes place from the thin-film transition region. Stephan and Busse [8] developed a model to describe the heat and mass transport in the microregion of the meniscus in a V-groove. Their numerical model agreed well with the measured heat transfer data and showed that up to $50 \%$ of the entire evaporation can take place in the microregion despite its small geometrical dimensions. Other researchers $[9,10]$ have attributed as much as $90 \%$ of heat transfer to the thin-film region. However, Park and Lee [11] suggested that the thin-film contributed less than $5 \%$ of total heat transfer due to its small geometrical extent. A recent model developed by Wang et al. [12] showed that $20 \%$ of

\footnotetext{
${ }^{1}$ Corresponding author.

Contributed by the Heat Transfer Division of ASME for publication in the JourNal OF Heat Transfer. Manuscript received May 11, 2008; final manuscript received January 26, 2009; published online April 2, 2009. Review conducted by Louis C. Chow.
}

the heat transfer takes place from the thin-film region, but as much as $60 \%$ of the overall heat transfer takes place from a $1 \mu \mathrm{m}$ thick microregion.

In terms of experimental investigations, interferometry and ellipsometry have been widely employed in the study of thin liquid films. Mirzamoghadam and Catton [13] considered a twodimensional (2D) meniscus generated on an inclined, partially submerged, heated flat plate in a pool of liquid. They studied the temperature in the liquid using laser holographic interferometry. The general characteristics of the meniscus region, where the combined influence of natural convection, conduction, and surface tension gradients are important, were deduced. Xu and Carey [9] assumed that heat transfer occurs only through the thin-film region and developed a model whose results were in reasonable agreement with their experiment. Dasgupta et al. [14] studied a 2D extended meniscus of heptane using ellipsometry and found high mass fluxes in the thin-film region using a semi-empirical model. However, their model neglected vapor diffusion effects. Panchamgam et al. [15] conducted interferometry experiments with pentane on a quartz substrate under saturation conditions and demonstrated for the first time that the disjoining pressure controls fluid flow within an evaporating, completely wetting, thin film.

Höhmann and Stephan [16] and Buffone and Sefiane [17] used liquid crystals to measure local temperatures underneath an evaporating meniscus. Thermochromic liquid crystals (TLCs) are organic compounds that reflect light when their temperature falls within a certain range, usually termed as their event temperature range. The color displayed by the TLCs can be related to the temperature of the surface. However, this technique suffers from large uncertainties and from the limited lifetime of the TLCs (ranging from a few minutes to $1-2 \mathrm{~h}$ ).

With advances in technology, infrared thermography is fast becoming an attractive option due to its nonintrusive nature, high resolution, and high temperature sensitivity. Jiang et al. [18] and Buffone and Sefiane [19] demonstrated temperature measurements on a meniscus surface with an infrared (IR) camera. Jiang et al. [18] carried out experiments on a thin film on a cylinder and concluded that nearly $20-40 \%$ of the heat transfer occurs through the thin-film region. It is to be noted that the actual emissivities of the surfaces were not considered in Refs. $[18,19]$, and all surfaces were assumed to have an emissivity of unity. The design of these experiments did not allow for the temperature distribution all 


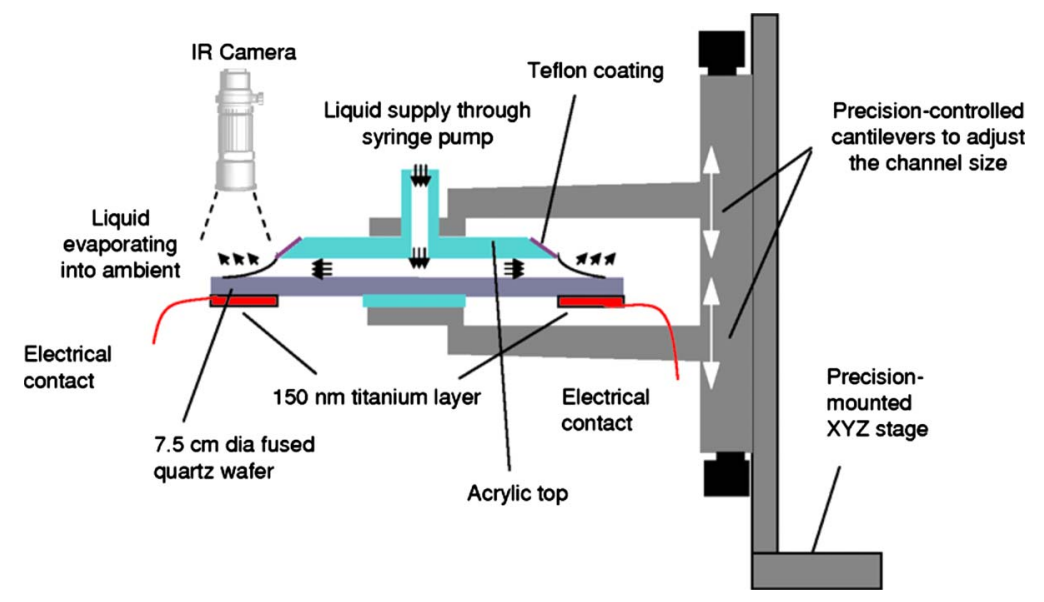

Fig. 1 Schematic diagram of the test setup in side view

along the meniscus to be obtained. The temperature drop in the all-important thin-film region was also not clearly observed.

In the present work, a steady two-dimensional meniscus in a channel subjected to a constant heat flux is studied. The fluid lost to evaporation is replenished using a syringe pump to achieve a constant evaporation rate. The effects of applied heat flux and evaporation rate on thin-film evaporation are investigated. A highend, science-grade IR camera is used for temperature measurements. This camera provides a spatial resolution of $\sim 6.3 \mu \mathrm{m}$ and a temperature sensitivity of $20 \mathrm{mK}$. The test setup allows for temperature measurements to be made right at the triple line; resolution to this scale has hitherto not been achieved. The measurements allow for critical parameters to be evaluated in situ and then used to obtain additional details concerning the evaporation process. A subregion of the meniscus of length $50 \mu \mathrm{m}$ is examined. A heat balance analysis is carried out to delineate the contribution of the subregion heat transfer to the total.

\section{Experimental Setup and Procedures}

2.1 Test Setup. Figure 1 shows details of the test setup. The vertical space between a $76.2 \mathrm{~mm}$ diameter, $500 \mu \mathrm{m}$ thick fused quartz wafer and a $58.42 \mathrm{~mm}$ outer diameter, $5.08 \mathrm{~mm}$ thick acrylic top piece acts as the channel of interest. This "channel" is mounted on a linear stage that enables precise control of the channel width (accuracy of $\sim 10 \mu \mathrm{m}$ ). A constant heat flux is provided to the thin film using a $100 \mathrm{~nm}$ titanium layer deposited on the underside of the quartz wafer with standard microfabrication procedures. The titanium heat source is annular in geometry with the annulus inner and outer diameters being $58.42 \mathrm{~mm}$ and $76.2 \mathrm{~mm}$, respectively. Liquid continuously fed from a syringe pump (PHD 2000, Harvard Apparatus) enters the test piece through an axial inlet, emerges from the slit, and forms a meniscus right above the heat source, causing it to evaporate into the atmosphere. The meniscus so formed has two solid-liquid-vapor junctions, one on the quartz wafer and the other at the edge of the acrylic top piece. The circular geometry naturally eliminates any edge effects that would be present in a rectangular domain.

Prevention of the formation of a thin film at the edge of the acrylic top piece proved to be challenging. Even a small amount of liquid spread on the acrylic formed liquid fingers because of microscopic surface irregularities, rendering difficult an accounting of the net liquid-vapor interfacial area. A hydrophobic Teflon coating on the angled edge of the acrylic was found to be effective in containing the liquid film precisely, without creeping on to the acrylic. An IR camera (Merlin, FLIR Inc.) with a $4 \times$ objective is used to capture the temperature contours and a goniometer (CAM 100, KSV Instruments Ltd.) with $2 \times$ magnification, and a backlit light emitting diode (LED) light is used to image the meniscus.
The IR camera was carefully calibrated with a high-sensitivity, high-stability blackbody (2000 series, SBIR Inc.). Performing an in situ calibration effectively removed the effect of background radiation.

High purity heptane (Sigma-Aldrich, $99.99 \%$ ), a highly wetting liquid with a boiling point of $98^{\circ} \mathrm{C}$, is used as the test fluid. The quartz wafer is solvent cleaned, blow dried with extra-dry grade nitrogen, and later rinsed with heptane before each run. To ensure that the system had reached a steady state, the evaporation process was allowed to occur for over $2 \mathrm{~h}$ in each test before recording data. Since the field of view of the IR camera, $2 \times 1.5 \mathrm{~mm}^{2}$, does not capture the entire annular region, images are taken at four different locations along the ring on the top and the bottom of the wafer to verify the uniformity of temperature along the perimeter of the meniscus. The absolute temperature distribution is found to be uniform within a confidence interval of $\pm 1^{\circ} \mathrm{C}$. All other subsequent experiments are conducted at a fixed location. Data sets in which any foreign particles were observed on the surface were discarded. Liquid menisci formed at three different evaporation rates and five different input power levels in two different channel widths are investigated for this work.

In order to determine the net applied heat flux, it is essential to estimate the heat losses in the system. The conduction losses through the wafer and the convection and radiation losses to the surroundings are estimated by performing a dry run. Wafer with no liquid in the system is tested. A series of tests at different power levels is conducted for this configuration, and the average steady-state heater temperature $\left(T_{\text {bottom }}\right)$ is recorded with the IR camera at each power level. A relationship between the input power and the heater temperature is then obtained as a curve fit to the results. The heat losses for each test with the liquid are then calculated by substituting the measured average heater temperature into the curve-fit relationship, and the heat input on the bottom of the channel $\left(q_{s}\right)$ is obtained by subtracting the losses from the input power. Thus estimated heat flux $q_{s}^{\prime \prime}$ is a function of the input power and the evaporation rate. However, no discernible difference is noted for $q_{s}^{\prime \prime}$ with variation in evaporation rate, and hence $q_{s}^{\prime \prime}$ is only a function of the input power. On average, the heat losses are found to be nearly $30-40 \%$ of the input power. The uncertainty in determining the input heat flux by this method is $\pm 10 \%$.

This analysis, however, does not take into account the heat lost to the liquid, in other words, the sensible heat gained by the liquid while flowing through the channel. As clarified later, this has a negligible impact on the heat transfer from the $50 \mu \mathrm{m}$ region. The uncertainty in the flow rate principally results from the step resolution of the syringe pump and is $\pm 0.35 \%$. 


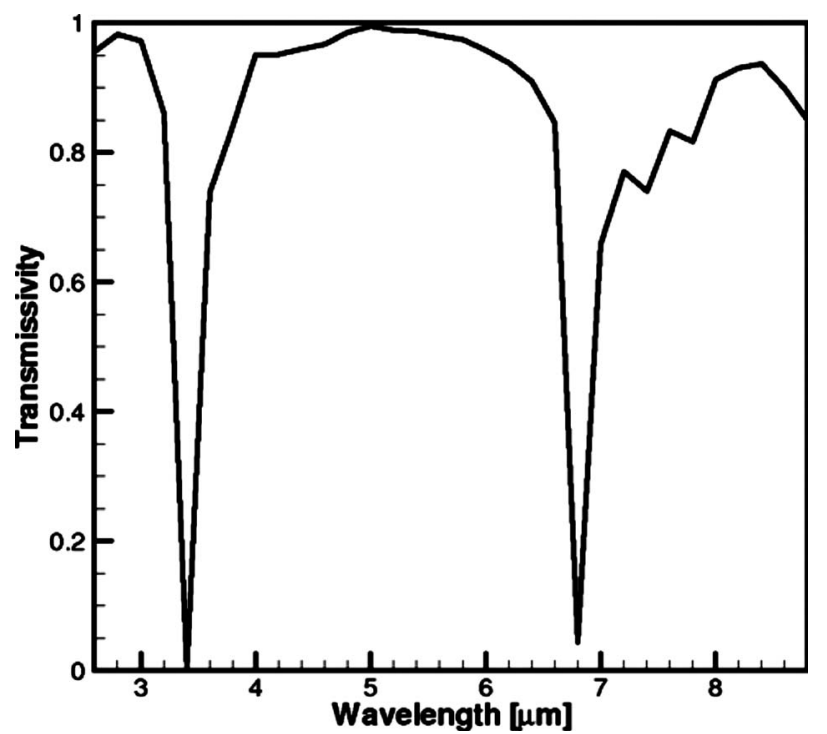

Fig. 2 Transmissivity of an $80 \mu \mathrm{m}$ thick heptane layer

2.2 Transmissivity of Heptane. Assuming the fluid to behave as a semitransparent solid [20], its transmissivity based on the complex index of refraction [21] in the infrared regime is calculated for obtaining an accurate estimation of liquid temperatures. Figure 2 shows the transmissivity of an $80 \mu \mathrm{m}$ thick heptane layer. It is noticed that the liquid remains nearly transparent in the bulk of the infrared regime $(3-8 \mu \mathrm{m})$.

Figure 3(a) shows the image of a heptane meniscus on a $500 \mu \mathrm{m}$ thick polished fused quartz wafer that is heated from below. Taking advantage of the IR transparency of heptane near the contact line, infrared measurements are used to capture the

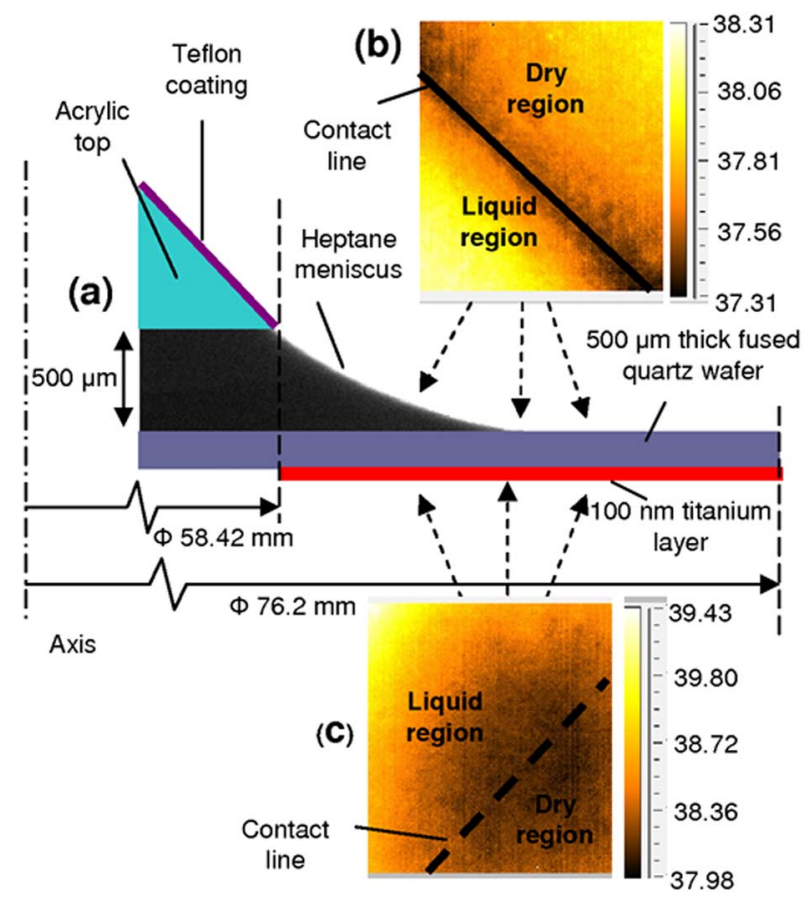

Fig. 3 (a) Image of heptane meniscus on fused quartz wafer $\left(q_{s}^{\prime \prime}=950 \mathrm{~W} / \mathrm{m}^{2}, \Psi=8.35 \times 10^{-7} \mathrm{~kg} / \mathrm{s}\right)$. (b) Infrared image of wafer top ( $\left.T_{\text {top }}\right)$ near the contact line. (c) Infrared image of the titanium layer on the underside of the wafer near the contact line $\left(T_{\text {bottom }}\right)$.

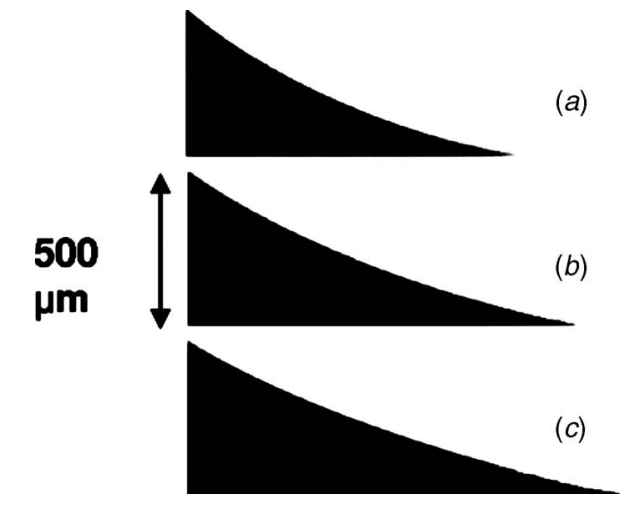

Fig. 4 Two-dimensional meniscus images at a heat flux of $990 \mathrm{~W} / \mathrm{m}^{2}$ and different evaporation rates: (a) 8.35 $\times 10^{-7} \mathrm{~kg} / \mathrm{s}$, (b) $8.8 \times 10^{-7} \mathrm{~kg} / \mathrm{s}$, and (c) $9.35 \times 10^{-7} \mathrm{~kg} / \mathrm{s}$

temperature of the wafer top surface $\left(T_{\text {top }}\right)$ and the temperature of the titanium layer on the underside of the meniscus $\left(T_{\text {bottom }}\right)$. Both these measurements are carried out with a single IR camera at different time periods after the system has attained steady state. As published values for emissivity for quartz and titanium span a range of values, an in situ calibration of the emissivities of both the surfaces is performed. This is achieved by coating half the surface with black paint (Krylon 1602) of known emissivity of 0.95 [22]. The wafer is then heated, and thermal images are recorded. Using the software RTOOLS (FLIR Inc.) and assuming that a $500 \mu \mathrm{m}$ long region at the interface between the black and the unpainted surface (i.e., the surface whose emissivity is desired) is at a uniform temperature, the emissivity of the nonblack surface is adjusted until it reads the temperature of the black surface. The emissivities were thus found to be 0.80 and 0.47 for the quartz and titanium layers, respectively.

A typical shape of the liquid-vapor interface is presented in Fig. $3(a)$, in which the liquid region is opaque and the air is transparent. Figures $3(b)$ and $3(c)$ are raw thermal images of the wafer top and titanium layer. The "liquid region" in the IR images corresponds to the wetted portion of the image while "dry region" indicates the superheated surface adjacent to the liquid meniscus. In both images, it is seen that the thin-film region near the contact line is the point of lowest temperature indicating its high efficiency. The temperature drop is less evident on the wafer underside than on the wafer top because of the smearing caused by the lateral conduction in the wafer. Similar temperature drops under the thin film were observed in Refs. $[16,17]$.

\section{Results and Discussion}

The dependence of meniscus shape, channel width, and temperature distribution near the meniscus on the heat flux and evaporation rate is first considered. The extent of heat transfer taking place from a $50 \mu \mathrm{m}$ long region near the contact line is then discussed.

3.1 Dependence of Meniscus Shape on Evaporation. The meniscus shape is an important parameter in determining the heat flux through the thin-film region [12]. The meniscus shape, and thus the effective area of evaporation, is varied in the experiments by controlling three independent parameters-evaporation rate $(\Psi)$, applied heat flux $\left(q_{s}^{\prime \prime}\right)$, and channel width $(w)$.

The effect of mass flow rate on the film profile at a constant applied heat flux of $990 \mathrm{~W} / \mathrm{m}^{2}$ is shown in Fig. 4. It is seen that the meniscus shape varies significantly with mass flow rate. At a constant heat flux, increasing the evaporation rate requires a larger interfacial area for evaporation, thereby changing the film profile. This is observed in Figs. 4(a)-4(c) where the contact line extends 


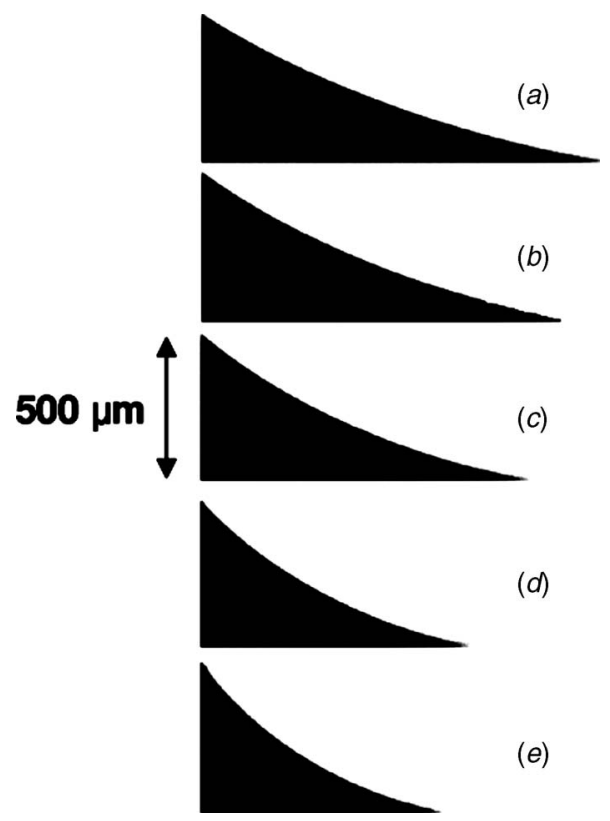

Fig. 5 Two-dimensional meniscus images at an evaporation rate of $8.35 \times 10^{-7} \mathrm{~kg} / \mathrm{s}$ and different heat fluxes: (a) $810 \mathrm{~W} / \mathrm{m}^{2}$, (b) $950 \mathrm{~W} / \mathrm{m}^{2}$, (c) $990 \mathrm{~W} / \mathrm{m}^{2}$, (d) $1030 \mathrm{~W} / \mathrm{m}^{2}$, and (e) $1190 \mathrm{~W} / \mathrm{m}^{2}$

forward with increasing evaporation rate. To evaluate the apparent contact angle, the profile of the meniscus is extracted from the digital images using an edge-detection algorithm in MATLAB [23]. A tangent to the curve-fitted profile at the contact line gives the contact angle. Thus evaluated apparent contact angles for all the cases are found to be in the range of 7-12 deg. The accuracy of the measurement technique is $\pm 1 \mathrm{deg}$.

The effect of heat flux on the film profile at a constant mass flow rate of $8.35 \times 10^{-7} \mathrm{~kg} / \mathrm{s}$ is illustrated in Fig. 5. At a constant evaporation rate, increasing the heat flux requires a smaller interfacial area for evaporation. This is observed in Figs. 5(a)-5(e) where the contact line recedes and the apparent contact angle increases with an increase in applied heat flux, which is in agreement with the trends found in Ref. [12]. A higher heat flux necessitates a higher capillary pressure gradient for intensive evaporation near the contact line and hence causes an increase in apparent contact angle.

The width of the channel was found to have only a minor effect on the film profile over the small range of widths tested, as demonstrated in Fig. 6; the effect of increasing the channel width from $500 \mu \mathrm{m}$ and $600 \mu \mathrm{m}$ is shown at identical values of heat flux and mass flow rate. The remaining results in this work consider only the channel width of $500 \mu \mathrm{m}$.

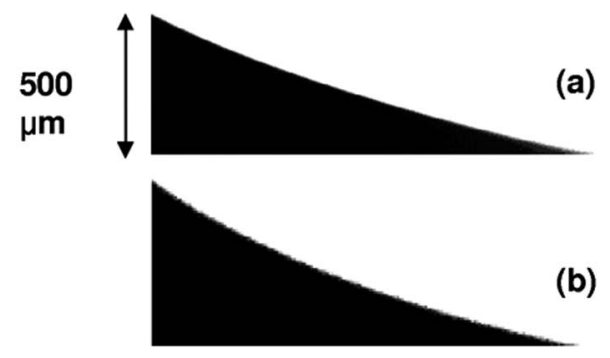

Fig. 6 Two-dimensional meniscus images at an evaporation rate of $9.35 \times 10^{-7} \mathrm{~kg} / \mathrm{s}$ and a heat flux of $820 \mathrm{~W} / \mathrm{m}^{2}$ in different channel widths: (a) $500 \mu \mathrm{m}$ and (b) $600 \mu \mathrm{m}$
3.2 Microscale Temperature Measurements. Figure 7 depicts the measured temperatures in a $400 \mu \mathrm{m}$ region surrounding the contact line at an applied heat flux of $1190 \mathrm{~W} / \mathrm{m}^{2}$ and at different evaporation rates. Each plot shows the time- and areaaveraged temperature distribution along the wafer top $\left(T_{\text {top }}\right)$, the wafer underside $\left(T_{\text {bottom }}\right)$, and the mean $\left(T_{\text {mean }}\right)$, where $T_{\text {mean }}$ is the mean of $T_{\text {top }}$ and $T_{\text {bottom. }}$. The $x$-axis represents the radial position, with the wetted and nonwetted regions identified (see Fig. $7(c)$ ). Only a subset of data points obtained is included to improve clarity. Each solid line represents the curve-fitted temperature, while the dotted-line envelopes represent the uncertainty in the measurements due to thermal noise and time- and area-averaging; several images are averaged to improve the confidence of the averaged temperatures.

As the heat flux is supplied from the titanium layer on the bottom, $T_{\text {bottom }}$ is greater than $T_{\text {top }}$ as expected. The lowest temperature point is at the contact line, signifying the sink effect and high efficiency of heat removal in the thin-film region. Lateral conduction in the quartz wafer leads to a smearing of the temperature valley on the underside; with a silicon wafer (of higher conductivity), the temperature valley is not observed. Höhmann and Stephan [16] observed a $\sim 0.2 \mathrm{~K}$ temperature drop near the contact line over a region of $35 \mu \mathrm{m}$ length on the underside of the wafer, but this was within the error limits of the measurement technique. Also, Jiang et al. [18] observed a $\sim 0.4 \mathrm{~K}$ temperature drop near the contact line over a region of $\sim 300 \mu \mathrm{m}$ length; however, because of experimental constraints only three data points were obtained over the region. The length over which the temperature drop is seen is a strong function of the experimental setup. The improved test setup used in the present work allows for a relatively large temperature drop of $\sim 1 \mathrm{~K}$ to be resolved on the wafer top over a length of $400 \mu \mathrm{m}$, as seen in Fig. 7.

It is noticed that the difference in temperature at the contact line between $T_{\text {top }}$ and $T_{\text {bottom }}$ decreases with an increase in evaporation rate, suggesting a decrease in effective thermal resistance with an increase in evaporation rate. Figure 8 illustrates the heat flux effect on the temperature contours near the contact line at a constant evaporation rate of $8.35 \times 10^{-7} \mathrm{~kg} / \mathrm{s}$. The plots reveal that the difference in temperature at the contact line between $T_{\text {top }}$ and $T_{\text {bottom }}$ increases with an increase in applied heat flux. This is in agreement with the results of Ref. [18].

3.3 Subregion Heat Transfer. While this is a multimode and three-dimensional heat transfer problem with conjugate conduction effects, an approximate heat balance analysis is carried out here based on the temperature measurements in Figs. 7 and 8 to obtain an estimate of the heat transfer through a small region near the contact line. A subregion of length $50 \mu \mathrm{m}$ (corresponding to a $\sim 10 \mu \mathrm{m}$ thick liquid layer) is defined as the region of interest. A heptane layer up to $80 \mu \mathrm{m}$ thick is essentially transparent to IR. Since this thickness is achieved at a distance of approximately $\sim 250 \mu \mathrm{m}$ along the wafer from the contact line, $T_{\text {top }}$ in the liquid region from $0 \mu \mathrm{m}$ (contact line) to $-250 \mu \mathrm{m}$ can be treated as the temperature of the wafer top surface.

Treating the wafer as a fin and assuming 1D conduction along its radius, an approximate heat transfer analysis is conducted. The 1D conduction assumption in the annular subregion is justified as the length of the subregion $(\sim 50 \mu \mathrm{m})$ is negligible compared with its radial position $\sim 59 \mathrm{~mm}$ (see Fig. 3). Neglecting heat losses, the heat balance for the control volume, shown in Fig. 9, is given by

$$
q_{r}-q_{r+\delta r}+q_{s}=q_{d}
$$

where $q_{r}$ is the heat conducted per unit depth in the $r$-direction, $q_{s}$ is the heat input on the bottom of the control volume per unit depth due to the electric heating, and $q_{d}$ is the heat dissipated per unit depth by evaporation from the meniscus. Using Fourier's law 

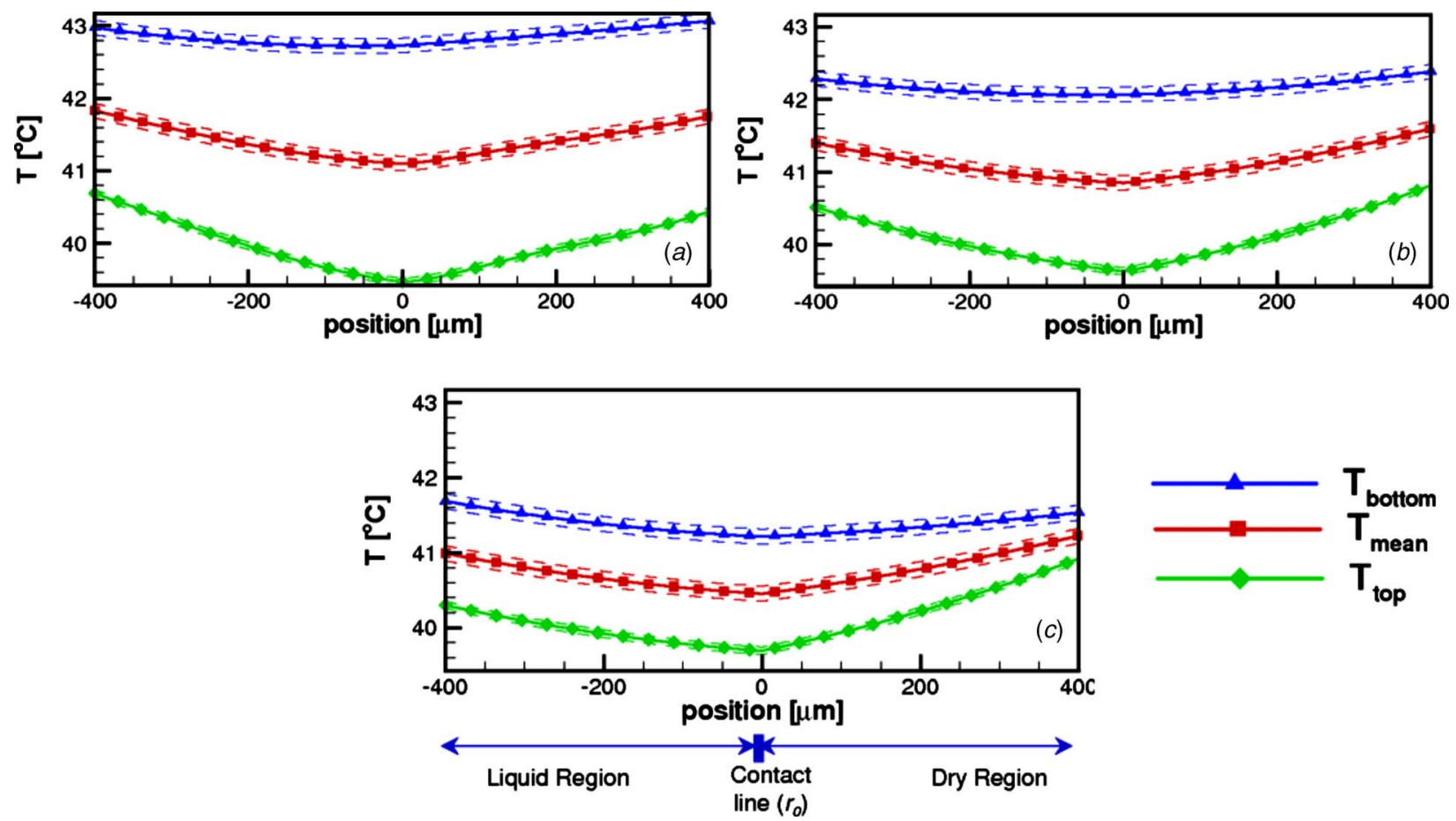

Fig. 7 Infrared temperature maps of $T_{\text {top }}$ and $T_{\text {bottom }}$ at a heat flux of $1190 \mathrm{~W} / \mathrm{m}^{2}$ and different evaporation rates: (a) 8.35 $\times 10^{-7} \mathrm{~kg} / \mathrm{s}$, (b) $8.8 \times 10^{-7} \mathrm{~kg} / \mathrm{s}$, and (c) $9.35 \times 10^{-7} \mathrm{~kg} / \mathrm{s}$

and assuming profiles of $T_{\text {mean }}$ such as those shown in Figs. 7 and 8 to represent the $1 \mathrm{D}$ temperature profiles in the wall, we have

$$
k \frac{d^{2} T_{\text {mean }}}{d r^{2}} t \delta r+q_{s}=q_{d}
$$

Since the heat source $q_{s}$ is of a constant value, when the dissipation heat flux $q_{d}$ reaches a maximum, $d^{2} T_{\text {mean }} / d r^{2}$ also reaches a maximum. The temperature maps in Figs. 7 and 8 show that the location of maximum $d^{2} T_{\text {mean }} / d r^{2}$ is at the contact line.

Integrating Eq. (2) along the length of the subregion $(\Delta r)$ and multiplying by the perimeter of the contact line gives the subregion heat transfer $\left(q_{\text {subregion }}\right)$ as

$$
q_{\text {subregion }}=q_{\mathrm{I}}+q_{\mathrm{II}}
$$

where
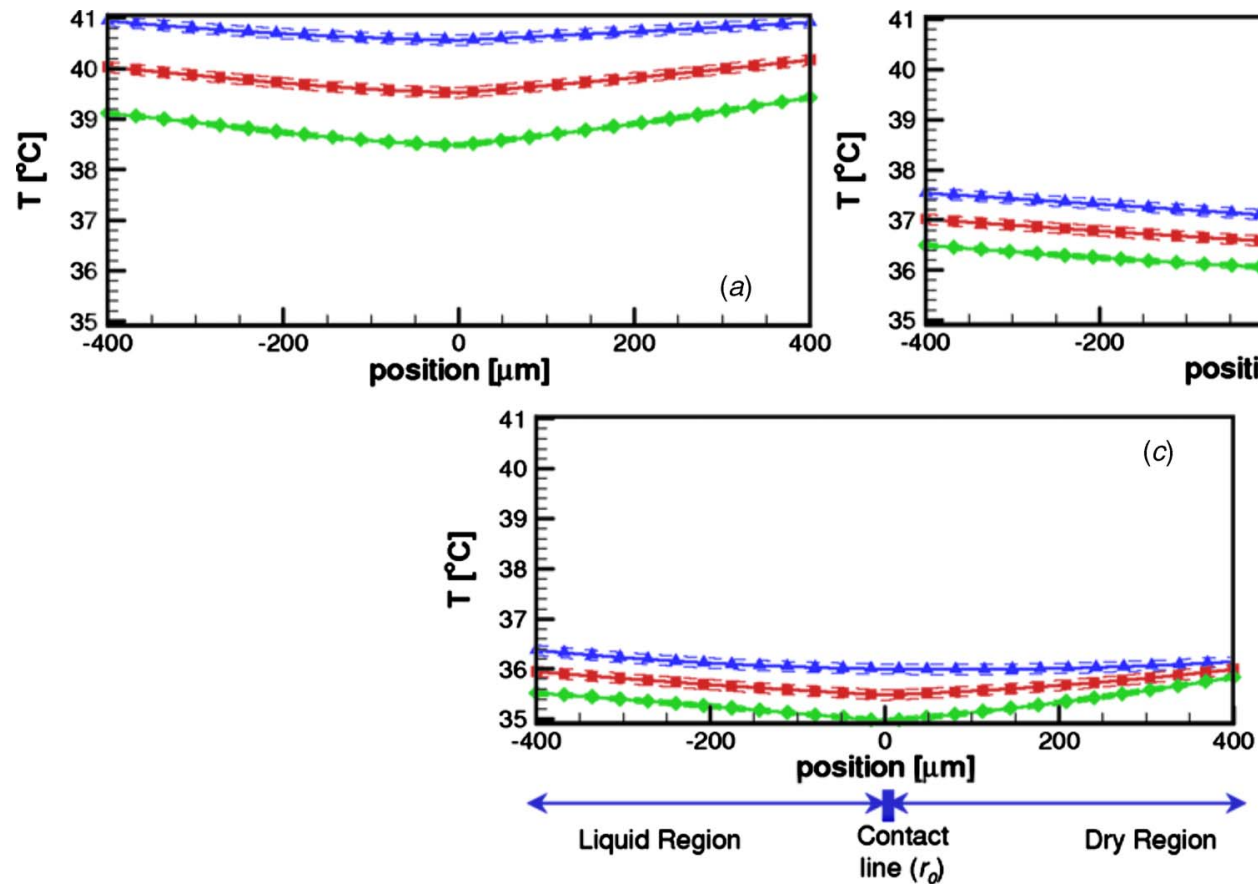
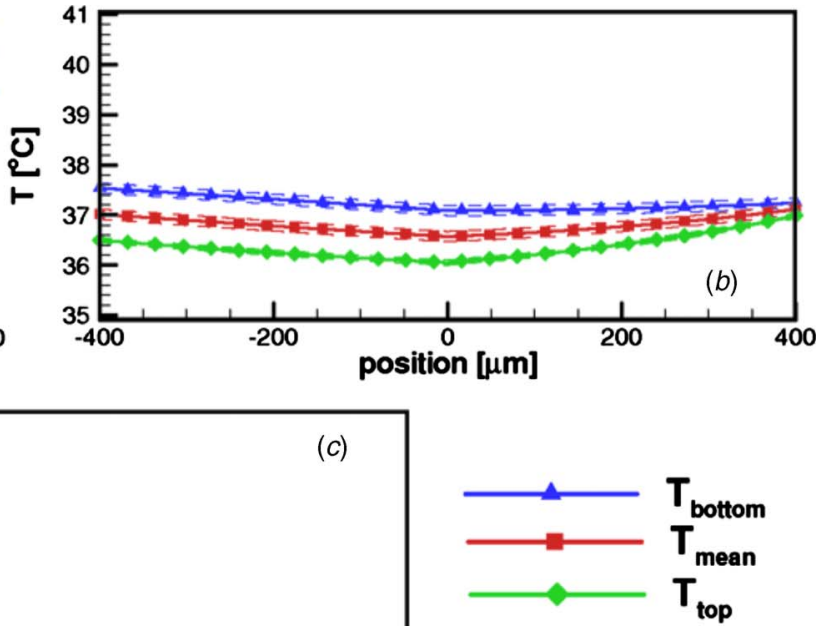

Fig. 8 Infrared temperature maps of $T_{\text {top }}$ and $T_{\text {bottom }}$ at an evaporation rate of $8.35 \times 10^{-7} \mathrm{~kg} / \mathrm{s}$ and different heat fluxes: (a) $1030 \mathrm{~W} / \mathrm{m}^{2},\left(\right.$ b) $950 \mathrm{~W} / \mathrm{m}^{2}$, and $(c) 810 \mathrm{~W} / \mathrm{m}^{2}$ 


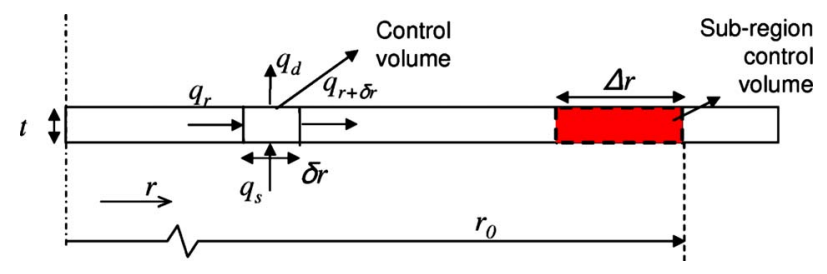

Fig. 9 The heat balance over a control volume of extent $\delta r$ in the wafer

$$
q_{\mathrm{I}}=\left(\left.k \frac{d T_{\text {mean }}}{d r}\right|_{r_{0}-\Delta r} ^{r_{0}} 2 \pi r_{0} t\right) \text { and } q_{\mathrm{II}}=\left(q_{s}^{\prime \prime} \Delta r 2 \pi r_{0}\right)
$$

where $d T_{\text {mean }} /\left.d r\right|_{r_{0}-\Delta r} ^{r_{0}}$ represents the difference in temperature gradient evaluated at the ends of control volume and $k$ is the thermal conductivity of the wafer. The first term in Eq. (3), $q_{\mathrm{I}}$, represents the heat conducted in from both sides of the control volume, while the second term $q_{\mathrm{II}}$ indicates the heat added from the heater. The fraction of heat being transferred through the meniscus subregion is given by

$$
\eta=\frac{q_{\text {subregion }}}{\Psi h_{f g}}
$$

Taking $k \sim 1.34 \mathrm{~W} / \mathrm{m} \mathrm{K}, t \sim 500 \mu \mathrm{m}, \Delta r \sim 50 \mu \mathrm{m}$, and $h_{f g}$ $\sim 350.6 \mathrm{~kJ} / \mathrm{kg}(320 \mathrm{~K}, 1 \mathrm{~atm})$, the values of $\eta$ are estimated. The uncertainty in the value of $\eta$ is estimated to be $\pm 10 \%$. For the case $q_{s}{ }^{\prime \prime}=810 \mathrm{~W} / \mathrm{m}^{2}$ and $\Psi=9.35 \times 10^{-7} \mathrm{~kg} / \mathrm{s}$, using the temperature data (Fig. 8(c)) and Eq. (3) gives $q_{\text {subregion }}=0.22 \mathrm{~W}, q_{\mathrm{I}}$ $=0.21 \mathrm{~W}$, and $q_{\mathrm{II}}=0.01 \mathrm{~W}$. This shows that the applied heat flux $\left(q_{\mathrm{II}}\right)$ contributes very little $(<5 \%)$ to the subregion heat transfer; similar behavior is observed in all the experimental results. Therefore, a small change in $q_{s}^{\prime \prime}$ does not change the value of $q_{\text {subregion }}$ and consequently of $\eta$. Table 1 summarizes the percentage contribution of subregion heat transfer to total heat transfer for all the experimental results obtained in this work. Nearly $70 \%$ of the heat is seen to be dissipated through the subregion. This value is in reasonable agreement with reports in the literature $[7,8,12]$. While a more rigorous analysis including vapor-diffusion-coupled evaporation [24] would yield a more accurate value of $\eta$, two important trends may be noted from the results in Table 1: $\eta$ increases with an increase in evaporation rate and an increase in heat flux. For a constant heat flux and with increasing evaporation rate, the average meniscus thickness in the subregion falls (see Fig. 4), thus bringing down the associated thermal resistance (as observed in Sec. 3.2) and enhancing $\eta$. As explained in Sec. 3.1, for a constant evaporation rate, the contact angle increases with an increase in heat flux. This increases the capillary pressure and consequently the liquid supply into the subregion, which results in an increase in $\eta$.

Table 1 Variation in the percentage contribution of the subregion heat transfer to the total $(\eta, \%)$ with heat flux $\left(q_{s}{ }^{\prime \prime}\right)$ and evaporation rate $(\Psi)$

\begin{tabular}{cccc}
\hline \hline & \multicolumn{3}{c}{$\Psi$} \\
\cline { 2 - 4 }$q_{s}^{\prime \prime}$ & $8.35 \times 10^{-7} \mathrm{~kg} / \mathrm{s}$ & $8.8 \times 10^{-7} \mathrm{~kg} / \mathrm{s}$ & $9.35 \times 10^{-7} \mathrm{~kg} / \mathrm{s}$ \\
\hline $810 \mathrm{~W} / \mathrm{m}^{2}$ & 66 & 67 & 69 \\
$950 \mathrm{~W} / \mathrm{m}^{2}$ & 70 & 73 & 78 \\
$990 \mathrm{~W} / \mathrm{m}^{2}$ & 68 & 73 & 78 \\
$1030 \mathrm{~W} / \mathrm{m}^{2}$ & 76 & 79 & 84 \\
$1190 \mathrm{~W} / \mathrm{m}^{2}$ & 77 & 80 & 87 \\
\hline \hline
\end{tabular}

\section{Conclusions}

A novel experiment has been designed to investigate the heat transfer characteristics of the thin-film region in a twodimensional meniscus. The effects of applied heat flux, evaporation rate, and channel width on thin-film evaporation are investigated. The liquid-vapor interfacial area increases with decrease in heat flux and increase in evaporation rate, and remains unaffected by small changes in channel width. Microscale infrared thermography revealed a distinct temperature drop at the triple line, indicating the effectiveness of thin-film heat transfer. This temperature drop was found to increase with increasing heat flux. An approximate heat balance analysis shows that nearly $70 \%$ of the heat transfer takes place from a subregion defined as a $50 \mu \mathrm{m}$ long extent of the meniscus adjacent to the contact line. The subregion heat transfer is found to increase with an increase in heat flux and increase in evaporation rate.

In an ongoing work, a micro-particle image velocimetry ( $\mu$ PIV) study is being conducted to visualize flow into the thin-film region so that the mass flow feeding evaporation may be more accurately determined. A comprehensive model and a numerical simulation of the experiment are also being developed.

\section{Acknowledgment}

The authors acknowledge financial support for this work from members of the Cooling Technologies Research Center, a National Science Foundation Industry/University Cooperative Research Center at Purdue University.

$$
\begin{aligned}
& \text { Nomenclature } \\
& \qquad \begin{aligned}
h_{f g} & =\text { latent heat of vaporization }(\mathrm{kJ} / \mathrm{kg}) \\
k & =\text { thermal conductivity }(\mathrm{W} / \mathrm{m} \mathrm{K}) \\
q_{s}^{\prime \prime} & =\text { applied heat flux }\left(\mathrm{W} / \mathrm{m}^{2}\right) \\
q_{\text {subregion }} & =\text { heat flow through the subregion }(\mathrm{W}) \\
T & =\text { temperature }\left({ }^{\circ} \mathrm{C}\right) \\
t & =\text { thickness of the wafer }(\mu \mathrm{m}) \\
w & =\text { channel width }(\mu \mathrm{m}) \\
r_{0} & =\text { distance of contact line from axis }(\mathrm{m})
\end{aligned}
\end{aligned}
$$

Greek Symbols

$$
\begin{aligned}
\eta & =\text { fraction of heat flow through the subregion }(\%) \\
\Psi & =\text { evaporation rate }(\mathrm{kg} / \mathrm{s}) \\
\delta r & =\text { differential length along the wafer } \\
\Delta r & =\text { length of the subregion }(\mu \mathrm{m})
\end{aligned}
$$

\section{Subscripts}

bottom $=$ titanium layer on the wafer underside

mean $=$ mean of top and bottom temperatures

subregion $=$ subregion near the contact line

top $=$ wafer top surface

\section{References}

[1] Potash, M., Jr., and Wayner, P. C., Jr., 1972, "Evaporation From a TwoDimensional Extended Meniscus," Int. J. Heat Mass Transfer, 15, pp. 18511863.

[2] Derjaguin, B. V., 1955, "Definition and the Concept of and Magnitude of the Disjoining Pressure and Its Role in the Statics and Kinetics of Thin Layers of Liquids," Colloid J. USSR, 17, pp. 191-197.

[3] Ward, C. A., and Duan, F., 2004, "Turbulent Transition of Thermocapillary Flow Induced by Water Evaporation," Phys. Rev. E, 69, p. 056308.

[4] Dhavaleswarapu, H. K., Chamarthy, P., Garimella, S. V., and Murthy, J. Y., 2007, "Experimental Investigation of Steady Buoyant-Thermocapillary Convection Near an Evaporating Meniscus," Phys. Fluids, 19, p. 082103.

[5] Wayner, P. C., 1999, "Intermolecular Forces in Phase-Change Heat Transfer: 1998 Kern Award Review," AIChE J., 45, pp. 2055-2068.

[6] Ma, H. B., and Peterson, G. P., 1996, "Experimental Investigation of the Maximum Heat Transport in Triangular Grooves," ASME J. Heat Transfer, 118, pp. $740-746$.

[7] Holm, F. W., and Goplen, S. P., 1979, "Heat Transfer in Meniscus Thin Film Transition Region," ASME J. Heat Transfer, 101, pp. 543-547.

[8] Stephan, P. C., and Busse, C. A., 1992, "Analysis of the Heat Transfer Coefficient of Grooved Heat Pipe Evaporator Walls," Int. J. Heat Mass Transfer, 35, pp. 383-391. 
[9] Xu, X., and Carey, V. P., 1990, "Film Evaporation From a Microgrooved Surface-An Approximate Heat Transfer Model and Its Comparison With Experimental Data," J. Thermophys. Heat Transfer, 4, pp. 512-520.

[10] Demsky, S. M., and Ma, H. B., 2004, "Thin Film Evaporation on a Curved Surface," Microscale Thermophys. Eng., 8, pp. 285-299.

[11] Park, K., and Lee, K., 2003, "Prediction of the Transport Phenomena in the Micro Capillary Tube of a CPL System," ASME International Mechanical Engineering Congress, Washington, D.C.

[12] Wang, H., Garimella, S. V., and Murthy, J. Y., 2007, "Characteristics of an Evaporating Thin Film in a Microchannel," Int. J. Heat Mass Transfer, 50, pp. 3933-3942.

[13] Mirzamoghadam, A. V., and Catton, I., 1988, "Holographic Interferometry Investigation of Enhanced Tube Meniscus Behavior," ASME J. Heat Transfer, 110, pp. 208-213.

[14] Dasgupta, S., Schonberg, J. A., and Wayner, P. C., Jr., 1993, "Investigation of Evaporating Extended Meniscus With Augmented Young-Laplace Equation," ASME J. Heat Transfer, 115, pp. 201-208.

[15] Panchamgam, S. S., Gokhale, S. J., Plawsky, J. L., Dasgupta, S., and Wayner, P. C., Jr., 2005, "Experimental Determination of Disjoining Pressure of Shear in the Contact Line Region of a Moving Evaporating Thin Film," ASME J. Heat Transfer, 127, pp. 231-243.
[16] Höhmann, C., and Stephan, P., 2002, "Microscale Temperature Measurement at an Evaporating Liquid Meniscus," Exp. Therm. Fluid Sci., 26, pp. 157-162.

[17] Buffone, C., and Sefiane, K., 2005, “Temperature Measurement Near the Triple Line During Phase Change Using Thermochromic Liquid Crystal Thermography," Exp. Fluids, 39, pp. 99-110.

[18] Jiang, J., Tao, Y.-X., and Byrd, L., 2000, "Evaporative Heat Transfer From Thin Liquid Film on a Heated Cylinder," Int. J. Heat Mass Transfer, 43, pp. $85-99$.

[19] Buffone, C., and Sefiane, K., 2004, "IR Measurements of Interfacial Temperature During Phase Change in a Confined Environment," Exp. Therm. Fluid Sci., 29, pp. 65-74.

[20] Viskanta, R., and Anderson, E. E., 1975, "Heat Transfer in Semitransparent Solids," Adv. Heat Transfer, 2, pp. 318-434.

[21] Tuntomo, A., Tien, C. L., and Park, S. H., 1992, "Optical Constants of Liquid Hydrocarbon Fuels," Combust. Sci. Technol., 84, pp. 133-140.

[22] NASA Jet Propulsion Laboratory Web Site, URL: http:// masterweb.jpl.nasa.gov/reference/paints.htm

[23] 2005, MATLAB, The Language of Technical Computing, Version 7.1, The Mathworks Inc., Natick, MA.

[24] Wang, H., Garimella, S. V., and Murthy, J. Y., 2008, "Transport From a Volatile Meniscus in a Microtube," Int. J. Heat Mass Transfer, 51, pp. 3007-3017. 